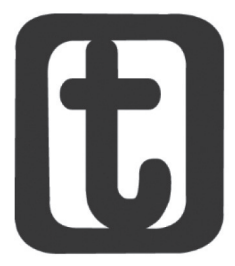

\title{
AGENDA FEMINISTA EM CONSTRUÇÃO E A DIREÇÃO EMANCIPATÓRIA DO CONJUNTO CFESS/CRESS
}

Feminist agenda in construction and the emancipatory direction of the CFESS / CRESS set

\section{Micaela Alves Rocha da Costa* Lizete Augusta Vidal Pereira Lopes Silva**} Andréa Lima da Silva ${ }^{* * *}$

(cC) BY-NC

\section{RESUMO}

O projeto ético-político do Serviço Social brasileiro, apesar de hegemônico no seio da categoria, não é homogêneo, o que implica no fato de que a não adesão de seus princípios por parte dos profissionais compromete, em partes, a sua materialização no cotidiano profissional. Considerando que o conjunto CFESS/ CRESS, enquanto entidade que direciona o exercício profissional dos assistentes sociais brasileiros, possui protagonismo na produção e disseminação de materiais que demarquem os valores defendidos pelo Serviço Social, buscamos neste artigo analisar a contribuição política dessa entidade para a consolidação da luta feminista, étnico-racial e da diversidade sexual na formação e no exercício profissional, realizada por meio de resoluções e publicações consideradas como fundamentais para o pensar e fazer profissional comprometidos com a

\footnotetext{
* Assistente social. Mestranda do Programa de Pós Graduação em Serviço Social da Universidade Federal do Rio Grande do Norte (UFRN, Natal, Brasil). E-mail: <micaelacost@gmail.com>.

** Assistente Social. Mestranda no Programa de Pós-Graduação em Serviço Social da Universidade Federal do Rio Grande do Norte. (UFRN, Natal, Brasil). Av. Senador Salgado Filho, 3000, Lagoa Nova, Natal/RN, Brasil, CEP 59072-970. E-mail: <liz_vidal83@hotmail.com>.

*** Assistente social. Pós-doutorado pelo Programa de Pós-Graduação em Políticas Sociais da Universidade de Brasília (UNB, Brasília, Brasil). Professora Adjunta da Universidade Federal do Rio Grande do Norte. (UFRN, Natal, Brasil). Av. Senador Salgado Filho, 3000, Lagoa Nova, Natal/RN, Brasil, CEP 59072-970. E-mail: <dealima18@gmail.com>.
} 
classe trabalhadora. Neste sentido, também destacaremos os impactos destes materiais para a categoria profissional. Este trabalho foi construído a partir da elaboração da dissertação de mestrado de uma das autoras e utilizou como metodologia pesquisa bibliográfica e documental na página oficial do CFESS, e entrevistas realizadas por meio de um roteiro semiestruturado, com docentes e discentes de universidades públicas e privadas do Rio Grande do Norte. Ressaltamos que a pesquisa foi submetida e aprovada pelo Comitê de Ética em Pesquisa do Hospital Universitário Onofre Lopes, respeitando a Resolução $n^{\circ}$ 466/2012 do Conselho Nacional de Saúde.

\section{PALAVRAS-CHAVE}

Feminismo. Serviço Social. Conjunto CFESS/CRESS.

\section{ABSTRACT}

The ethical-political project of the Brazilian Social Work, although hegemonic within the category, is not homogeneous, which implies that the non-adherence of its principles by professionals compromises, in parts, its materialization in the professional daily life. Considering that the CFESS / CRESS group, as an entity that directs the professional practice of Brazilian social workers, has a leading role in the production and dissemination of materials that demarcate the values defended by Social Work, we seek in this article to analyze the political contribution of this entity to the consolidation of feminist, ethnic-racial struggle and sexual diversity in the formation and the professional exercise, realized through resolutions and publications considered as fundamental for the thinking and doing professional committed to the working class. In this sense, we will also highlight the impacts of these materials for the professional category. This work was based on the elaboration of the master's dissertation of one of the authors and used as methodology bibliographical and documentary research in the official page of the CFESS, and interviews conducted through a semi-structured script, with teachers and students of public and private universities of the Rio Grande do Norte. We emphasize that the research was submitted and approved by the Research Ethics Committee of University Hospital Onofre Lopes respecting Resolution No. 466/2012 of the Brazilian Health Council.

\section{KEYWORDS}

Feminism. Social Work. CFESS/CRESS set.

Submetido em: $x x / x / 2017$

Aceito em: $x x / x x / 2017$

\section{INTRODUÇÃO}

O tempo é de barbárie generalizada, da destruição total dos direitos da classe trabalhadora sob o comando do sistema do capital em seu momento contemporâneo de crise cuja produção metabólica e projeto de acumulação são destrutivos para a humanidade. 
No momento atual de intensos retrocessos dos direitos sociais, em que a violência e a intolerância são legitimadas por amplos setores da sociedade e a barbarização da vida social se intensifica há uma necessidade urgente e importante de posicionamentos políticos que defendam os direitos da classe trabalhadora e as pautas históricas de suas lutas, se tornam cada vez mais urgentes.

O conjunto composto pelo Conselho Federal e os Conselhos Regionais de Serviço Social (CFESS/CRESS), cumprem um importante papel na produção e disseminação de documentos que direcionem o exercício profissional do assistente social no horizonte da defesa dos direitos humanos e sociais, ainda que reconhecendo os limites da sociabilidade capitalista. Entidades estas, comprometidas com os interesses da classe trabalhadora, e cujo projeto profissional aponta para a construção de uma sociabilidade livre da opressão/exploração da vida humana, mediante espaços de resistência que são fundamentais para estarmos sintonizados com os valores sociais historicamente construídos, na luta por outra sociabilidade.

Assim, fundamentada pela teoria social crítica, que permite compreender a totalidade na qual estão inseridas mulheres, negras e negros, indígenas, população de Lésbicas, Gays, Bissexuais, Travestis, Transexuais e Transgêneros (LGBT), entre outros sujeitos; é possível analisar o sistema de exploração e dominação em que estes sujeitos estão inseridos, traçando estratégias para o enfrentamento ao patriarcado, ao machismo, ao racismo e a homofobia. Nesse sentido, entendemos o feminismo, a luta pela igualdade racial e pela diversidade sexual como pautas fundamentais para a luta e efetivação dos direitos humanos e elegemos a página oficial do Conselho Federal de Serviço Social (CFESS) como um canal fundamental para a comunicação entre a entidade e a categoria que produz importantes materiais, a exemplo do CFESS Manifesta.

As reflexões e análises contidas neste artigo são partes constitutivas de uma pesquisa de mestrado que objetivou analisar os avanços, contradições e rebatimentos da discussão de gênero e feminismo na formação profissional em Serviço 
Social e como parte desta análise apreender a visibilidade e a apropriação do conteúdo político dos materiais e das campanhas defendidas pelo conjunto CFESS/CRESS por parte das entrevistadas, sendo o seu conteúdo analisado por meio da análise de conteúdo.

\section{O SURGIMENTO DO CONJUNTO CFESS/CRESS: POR ONDE A LUTA COMEÇA}

Ao resgatarmos o processo de construção do que conhecemos, na atualidade, como o Conjunto CFESS/CRES precisamos, inicialmente, refletir sobre o cenário histórico situado a partir de meados da década de 1960, cujos moldes de um Estado intervencionista, autoritário e regulatório exerceram forte influência na formação e consolidação não só dos Conselhos Profissionais, mas da própria legitimação e atuação do Serviço Social Brasileiro.

O Serviço Social foi uma das primeiras profissões na área social a ter uma Lei de Regulamentação aprovada (Lei 3252, de 27 de agosto de 1957), e, a partir de 1962, com a aprovação do decreto 994 de 15 de maio, houve a constituição do conjunto composto pelo Conselho Federal de Assistentes Sociais (CFAS) e os Conselhos Regionais de Assistentes Sociais (CRAS), responsáveis pela disciplina e fiscalização do exercício profissional.

Nesse momento histórico, as práticas conservadoras de um Serviço Social acrítico e funcional ao Governo vigente atuava de maneira policialesca e controladora, o que reflete, na atuação dos Conselhos, tanto em sua atividade de fiscalização da profissão, quanto nas possibilidades de articulação política da categoria, já que a repressão da ditadura militar impedia quaisquer ações questionadoras da ordem vigente.

Pouco tempo após a sua criação, o então CFAS, compromissado com a atividade da fiscalização e reconhecendo não haverem instrumentos legais satisfatórios para o seu exercício, passa a promover, a partir de 1966, encontros nacionais do conjunto 
CFAS/CRAS" “[...] nos quais são discutidas pautas comuns, objetivando aprimorar o desempenho do Conjunto em exercer sua função regulatória e fiscalizadora" (ABREU, 2013, p. 58). Esse empenho, no entanto, não trouxe mudanças substancias a atividade da fiscalização exercida pelos Conselhos, que se limitavam, apenas, a exigir dos profissionais o pagamento dos tributos e a inscrição na entidade.

Esse viés conservador, que perpassa a profissão dos primeiros anos de sua criação até a década de 1960, começa a ser indagado pela vanguarda profissional, que inicia o processo de repensar a sua prática e a questionar o posicionamento de subalternidade da profissão frente às classes dominantes.

Essa situação teve seu auge a partir do Congresso da Virada (III (BAS), em 1979, quando o conservadorismo expresso por alguns setores da profissão foi duramente questionado e enfrentado pela categoria que, inspirada pelas lutas sociais na ditadura militar, vivenciava um período de intensa transformação profissional $^{2}$. Alguns desdobramentos incidirão diretamente sobre a organização profissional, visto que,

É nesse contexto que o processo de ruptura incide sobre a objetividade dos profissionais, em sua inserção nos espaços sócio-ocupacionais da profissão, na condição de trabalhador assalariado, partícipe do trabalho coletivo socialmente combinado, que vende sua força de trabalho como todo trabalhador. De outro lado, esse processo recai sobre a subjetividade da categoria profissional que se manifesta em sua organização político-sindical, na formação e no exercício profissional e na representação estudantil, que imprime uma direção social à profissão, expressa

\footnotetext{
1 É importante pensar no significado "endógeno" desse momento histórico para o Serviço Social, quando a profissão era pensada de maneira corporativista, o que, em nossa reflexão, contribui para justificar o nome que é dado aos Conselhos Federal e Regionais.

2 A gênese da concepção de profissão de intenção de ruptura com o conservadorismo tem raízes na Reconceituação latino-americana, com experiências profissionais no Chile e na Argentina, que se espraiam por outros países da América Latina e do Caribe; com forte oposição ás ditaduras militares do continente e formulação de novas bases conceituais para uma ação profissional crítica (ABRAMIDES; CABRAL, 2009, p. 61). No Brasil, destacamos a luta dos estudantes de Serviço Social, organizados na Subsecretaria de Serviço Social na União Nacional dos Estudantes (SESSUNE), que também contribuíram diretamente para este processo de transformação do Serviço Social.
} 
no compromisso com os interesses imediatos e históricos da classe trabalhadora (ABRAMIDES; CABRAL, 2009, p. 55).

Com isso, a categoria profissional legitima a ruptura ${ }^{3}$ conservadora por dentro da profissão e inaugura um novo tempo no Serviço Social brasileiro: a defesa da classe trabalhadora através de uma perspectiva classista, com a aproximação da teoria marxista4. Netto (1999) afirma que "A luta política, na sociedade brasileira, [...] criou o quadro necessário para quebrar o quase monopólio do conservadorismo no Serviço Social: no processo da derrota da ditadura inscreveu-se [...] a condição política para a constituição de um novo projeto profissional" (NETTO, 1999, p. 100).

Temos, assim, que, ao longo das décadas de 1980 e 1990, tornouse possível, dado o compromisso da vanguarda em defender os interesses das classes trabalhadoras (na qual os assistentes sociais também estão inseridos); a renovação/reconstrução de instrumentos normativos que direcionassem a prática e a formação profissional numa perspectiva de emancipação e liberdade da pessoa humana, pensando-as em sua totalidade: política, econômica, cultural e social. Boschetti (2009, p. 146) diz que "Esse foi o sentido da 'virada', romper com o autoritarismo conservador e ousar lutar para construir um projeto de profissão articulado a um projeto societário anticapitalista [...]", livre da opressão, da exploração do homem pelo homem, o qual haja justiça e equidade.

O empenho da categoria em debater e construir esse projeto profissional voltado para a defesa dos interesses da classe trabalhadora, bem como o avanço teórico-político alcançado em meio aos processos de militância e a recusa ao conservadorismo profissional; leva o coletivo de assistentes sociais, que estava a frente das entidades representativas, a reunir os profissionais

\footnotetext{
3 Não podemos pensar essa ruptura como um processo finalizado. Antes, é necessário que haja o reconhecimento de que, em uma sociedade conservadora, os valores e princípios que estão sendo reproduzidos e resignificados, por serem conservadores, requerem um enfrentamento cotidiano. Por isso, quando nos referimos à ruptura do Serviço Social com o conservadorismo, estamos demarcando o período da trajetória dessa profissão quando, coletivamente, decidimos lutar pela construção de um projeto profissional de valores emancipatórios.

4 Segundo Netto (1989, p. 97 Indicar entre aspas duplas o trecho citado), “[...] a aproximação não se deu as fontes marxianas e/ou aos clássicos da tradição marxista, mas especialmente a divulgadores e pela via de manuais de qualidade e níveis discutíveis."
} 
para discutirem a revisão dos instrumentos jurídico-políticos que sustentam esse Projeto: o Código de Ética e a Lei de Regulamentação (Lei 8662/93) da Profissão, ambos defasados em seu conteúdo para a perspectiva que nutria os princípios firmados a partir desse momento. Esta lei redefine, também, o nome do CFAS, passando a ser denominado por Conselho Federal de Serviço Social (CFESS) e o CRAS, que passa a ser denominado por Conselho Regional de Serviço Social (CRESS), perdendo o seu caráter corporativista também no nome de suas entidades representativas.

Além disso, a Lei 8662/93 determina as competências e atribuições específicas do assistente social e regulamenta os encontros nacionais do conjunto CFESS/CRESS como instância de deliberação máxima da categoria profissional. Essa mudança modifica não apenas o funcionamento dos conselhos, mas a própria atividade de fiscalização do exercício profissional, que perde o seu caráter meramente policialesco de outrora. Outro ponto importante é o fato de que essa entidade passa a defender, conjuntamente, os direitos sociais, as políticas públicas e o acesso destes à classe trabalhadora, dentre outros. A mudança do conjunto também inaugura uma nova relação entre a direção das entidades e a base, no sentido em que a comunicação entre estes dois sujeitos recebe um novo sentido político: a democratização da informação como instrumento para a transformação da sociedade. Dessa forma,

\begin{abstract}
O amadurecimento da compreensão do significado social da profissão, a tradição teórica que permite a leitura da realidade em uma perspectiva sóciohistórica, as respostas da profissão à conjuntura e apontam para a consolidação de um projeto de profissão vinculado às demandas da classe trabalhadora (ASSOCIAÇÃO BRASILEIRA DE ENSINO E PESQUISA EM SERVIÇO SOCIAL, 2017, não paginado).
\end{abstract}

Esse período marcado por profundas transformações também assinala a construção do projeto ético-político profissional, que busca consolidar a direção social construída pelos profissionais cotidianamente. A lei de regulamentação da profissão, o Código de Ética profissional e as Diretrizes Curriculares ${ }^{5}$ embasam esse

5 As Diretrizes Curriculares estão pautadas por um projeto de formação profissional, coletivamente 
projeto e guiam os profissionais à reflexão crítica e a construção cotidiana de ruptura com o conservadorismo. De acordo com Boschetti (2009, p. 153),

[...] a organização política das entidades nacionais de Serviço Social no Brasil, como o Conjunto CFESS/ CRESS, a ABEPSS e a ENESSO, é uma mediação fundamental para o estabelecimento de relação entre o projeto profissional e um projeto societário comprometido com uma nova sociabilidade.

Nesse sentido, os ganhos políticos oriundos destas mudanças permanecem em construção pela categoria, fortalecendo o Serviço Social na medida em que possibilita estratégias para o pensar e o fazer profissional crítico, combativo e comprometido com a classe trabalhadora.

Os desafios impostos para o Serviço Social no tempo presente têm exigido uma maior articulação e organização da categoria na defesa dos direitos humanos e a comunicação tem sido uma estratégia fundamental nessa perspectiva de luta.

A Política Nacional de Comunicação do conjunto CFESS/CRESS tem sido indispensável no processo de democratização das informações na construção das lutas travadas pela categoria, possuindo como princípios alguns pontos fundamentais, tais como:

[...] a comunicação como bem público, em contraposição ao monopólio e à mercantilização existente no Brasil; a comunicação como direito humano, devendo constituir-se como espaço de denúncia a toda forma de opressão, violação e desrespeito aos direitos humanos; o reconhecimento da dimensão política da comunicação, devendo esta ser utilizada em seu caráter de socialização da informação, denúncia e resistência; a utilização da comunicação para o fortalecimento dos movimentos sociais e da classe trabalhadora na perspectiva crítica e emancipatória; entre outros (CONSELHO FEDERAL DE SERVIÇO SOCIAL, 2011, p.20-21).

construído, ao longo dos anos 80 e 90 . Estas estabelecem uma base comum, no plano nacional, para os cursos de graduação em Serviço Social e objetivam oferecer capacitação teórico-metodológica, ético-política e técnico-operativa para a formação profissional (ASSOCIAÇÃO BRASILEIRA DE ENSINO E PESQUISA EM SERVIÇO SOCIAL, [201?]). 
Assim, o papel cumprido pelo conjunto CFESS/CRESS em disseminar e disponibilizar, através da internet, o material produzido é importantíssimo. Pois é por meio da divulgação e da disponibilização das Resoluções e demais instrumentos jurídico-normativos (como o Código de Ética, a Lei de Regulamentação, alguns Pareceres Jurídicos), bem como das cartilhas produzidas ("Meia formação não garante um Direito", "Educação não é fastfood"), dos parâmetros de atuação para o trabalho do assistente social em algumas áreas (sócio jurídica, assistência social, saúde) e dos CFESS Manifesta (cujo conteúdo perpassa o posicionamento e a defesa de temáticas relacionadas ao aborto, à LGBTfobia, ao ataque aos direitos sociais, dentre outros), que os assistentes sociais tem contato com os valores e princípios defendidos pela profissão, e podem, também, se instrumentalizar ético-politicamente na defesa de seu exercício profissional, fortalecendo, assim, o projeto ético-político. Aos CRESS, por meio da fiscalização e sua dimensão pedagógica, cabe, também, essa divulgação e disseminação.

\section{A AGENDA FEMINISTA DO CONJUNTO CFESS/CRESS EM PERMANENTE CONSTRUÇÃO}

Conforme exposto, inúmeras lutas foram encampadas pela categoria a fim de consolidar o Serviço Social no Brasil ao longo destes anos. Outras tantas lutas permanecem sendo travadas na categoria profissional, atualizando a profissão no tempo presente, juntamente ao compromisso ético político com a classe trabalhadora. Neste campo da efetivação dos direitos, destacamos a contribuição do feminismo ${ }^{6}$, para a profissão e do Serviço Social para a luta feminista, considerando esta como parte integrante da luta por direitos humanos.

A relação do feminismo com o Serviço Social é contemporânea ao processo de consolidação da profissão, todavia, desde sua gênese, as mulheres estão presentes na categoria, trazendo neste processo

6 Compreende-se que o feminismo "[...] é ao mesmo tempo uma teoria que analisa criticamente o mundo e a situação das mulheres, um movimento social que luta por transformação e uma atitude pessoal diante da vida" (SILVA; CAMURÇA, 2010, p. 9). Cabe ressaltar que o feminismo possui em sua essência uma unidade de diversidades, dispondo de diversas teorias e características, que incidem diretamente na forma de organização política. Conforme aponta Cisne (2014, p. 59), "[...] o movimento feminista, entretanto, possuí em seu seio uma diversidade de perspectivas, tanto no que diz respeito à dimensão teórica, como política." 
de construção, particularidades inerentes a divisão sexual do trabalho, ao patriarcado, ao machismo e, também, contribuições para a luta pelo fim da opressão e da exploração. Como sabemos, na gênese da profissão, o perfil exigido pela Igreja ao selecionar militantes para as atividades assistencialistas era composto essencialmente por mulheres, sendo fortemente prestigiada a prática caritativa que deveria ser aperfeiçoada através do estudo cujas bases eram neotomistas, dogmáticas e conservadores. $\mathrm{O}$ Serviço Social Tradicional estava diretamente ligado ao Projeto de retomada do poder político e ideológico que a Igreja Católica vinha perdendo. Pensar na ação do Serviço Social era, sobretudo, pensar no trabalho ofertado por mulheres burguesas, militantes católicas e de moral conservadora.

Este perfil de forte cunho marianista ${ }^{7}$ vai se inserir significativamente na constituição do Serviço Social, naturalizando a bondade e a abnegação como elementos femininos e inerentes as assistentes sociais. Ressaltamos estes aspectos aqui para evidenciar a forma pela qual a inserção das mulheres na área profissional esteve articulada ao conservadorismo e ao pensamento patriarcal na sociabilidade capitalista. De acordo com Cisne (2004),

A subordinação da mulher e os dons ou habilidades ditas femininas são apropriados pelo capital para a exploração da força de trabalho, pois, as atividades e trabalhos desenvolvidos por mulheres - ao serem vistos como atributos naturais, extensões de habilidades próprias do gênero feminino - são consideradas dons e não trabalho (CISNE, 2004, p. 127).

Assim, a identidade profissional tem em suas raízes históricas um forte posicionamento conservador, em que a representação da mulher ideal é santificada e o fazer profissional pautado em um cunho humanista e conservador.

É a partir da década de 1960, que as bases teóricas tradicionais e práticas profissionais começam a ser questionadas pela categoria. O trabalho junto aos movimentos sociais, organizações e partidos 
políticos, permitiu uma aproximação da profissão ao marxismo. Esse processo após 1980 sinalizou as lutas feministas como um elemento importante para as mulheres, para os movimentos sociais e para a categoria profissional, que passou a enxergar a potencialidade do feminismo na construção das lutas pelo fim das formas de opressão e exploração. Nesse sentido, a contribuição feminista para a profissão tem sido de extrema relevância, considerando que as pautas oriundas dos movimentos feministas, tal como a descriminalização do aborto, a luta pelo fim da violência contra a mulher, o fim da exploração sexual, entre tantas outras, passam a somar-se às lutas da categoria profissional.

Esse movimento é imprescindível para o Serviço Social, visto que o avanço do conservadorismo tem atingido a profissão, ameaçando os valores coletivamente construídos pela categoria, minimizando o combate a todo tipo de opressão e discriminação, seja por gênero, classe, raça/etnia, orientação sexual ou identidade de gênero. É importante para a categoria pautar a discussão feminista no Serviço Social, pois, se temos em vista alcançar no horizonte um projeto societário sem exploração e dominação de classe, esse projeto precede a construção de uma cultura feminista. Por sua vez, o feminismo também pode contribuir com a construção do projeto profissional da profissão, uma vez que

O processo de renovação do Serviço Social é também tributário da luta pela emancipação das mulheres na sociedade brasileira, que renasce com vigor no combate ao último período ditatorial, em parceria com as lutas pelo processo de democratização da sociedade e do Estado no país (IAMAMOTO, 2011, p. 105).

Para, além disso, cabe destacar que a discussão feminista também envolve a discussão sobre a luta pela igualdade racial e diversidade sexual, pois, no sistema capitalista, o machismo, o racismo e a homofobia se misturam e se expressam em diversas e complexas formas e contradições. Conforme apontam os estudos de Saffioti (1987, 2004), na sociedade de classes, há uma simbiose entre o patriarcado, o machismo e o racismo que não pode ser fragmentada e que incide diretamente sobre a vida das mulheres.

Desde modo, com o objetivo de identificar a construção da pauta feminista dentro do conjunto CFESS/CRESS nos debruçaremos 
sobre algumas ações da entidade, com a finalidade de apreender as principais discussões que tem sido realizadas no que se refere às temáticas supracitadas.

Dessa forma, deteremos nossa análise nos materiais publicados no site do CFESS, tais como: o boletim CFESS Manifesta, as resoluções divulgadas pela entidade, as peças temáticas e algumas publicações que tenham como cerne a temática feminista, étnico-racial e de diversidade sexual, visto que estas categorias estão diretamente relacionadas na luta contra a opressão e a exploração.

A análise na página oficial do CFESS, que vem sendo construída desde 2004 pelas gestões que passaram pelo conselho é utilizada como fonte de pesquisa, pois, consideramos a dificuldade de acesso aos materiais anteriores à criação da página. Além disso, consideramos que a popularização da internet, possibilitou a visibilidade das redes sociais do conjunto, bem como suas ações pela categoria profissional.

O CFESS MANIFESTA é um boletim que expressa o posicionamento político ${ }^{8}$ do CFESS a partir de alguma temática ou situação que seja pertinente ao trabalho profissional ou as lutas sociais na conjuntura. O primeiro boletim foi lançado em 15 de setembro de 2004 e traz como pauta a luta contra o projeto de lei do ato médico. Desde então, diversas temáticas tem sido trabalhadas, tais como: direitos da criança e do adolescente; violência contra a mulher; luta pela reforma urbana e direito a cidade; reforma agrária; dia do trabalhador; dia do orgulho LGBT; luta pela descriminalização e legalização do aborto; população em situação de rua; conferências nacionais de assistência social; entre inúmeros outros temas.

8 É importante ressaltar que os posicionamentos políticos expressos pelos CFESS Manifesta encontram a resistência de profissionais que discordam das pautas reivindicadas pelas entidades que representam a categoria, o que se justifica pela compreensão de sermos, enquanto categoria, um sujeito coletivo diverso, cujos valores defendidos não necessariamente coincidem com aqueles construídos hegemonicamente ao longo dos últimos 38 anos de profissão. Como consequência dessa resistência, podemos encontrar uma pouca disseminação desse material entre os assistentes sociais de base, como uma maneira de contraposição às defesas explicitadas no conteúdo desse boletim. Entretanto, tal contraposição encontra nos instrumentos legais (código de ética, lei de regulamentação, resoluções) que direcionam o exercício profissional, um claro limite, uma vez que a observância e o cumprimento das normativas expressas nesses materiais é um dever de todo assistente social. Nesse sentido, é importante compreender que os posicionamentos expressos pelo CFESS Manifesta estão sempre em concordância com os valores e princípios que direcionam os dispositivos legais que normatizam a profissão de assistente social no Brasil. 
De setembro de 2004 até 17 de julho de 2017 foram contabilizados 154 boletins lançados na aba "Publicações" na página do CFESS. Desse total, 38 boletins discorrem acerca das seguintes temáticas: as conferências nacionais LGBT'S; a Lei Maria da Penha; o Dia da visibilidade lésbica; o Dia latino-americano e caribenho de luta pela descriminalização e legalização do aborto; o Dia Internacional de combate à violência contra a mulher; o Dia nacional da consciência negra; o tráfico e à exploração de mulheres e crianças; o trabalho doméstico; a diversidade trans; os direitos humanos (com recorte aos direitos das mulheres), entre outros.

Deste modo, é possível verificar que $25 \%$ do conteúdo trabalhado no CFESS Manifesta se referem ao feminismo, questão étnicoracial e diversidade sexual. Nota-se que estas temáticas têm sido trabalhadas de forma contínua, agregando elementos da realidade que incidem diretamente sobre a vida das mulheres, tal como: a violência, o desemprego, a precarização do trabalho, o acesso à saúde, etc. Esse percentual mostra que a atualidade do feminismo se mantém presente no posicionamento do CFESS, indicando sua pertinência para a profissão.

Também consideramos que a linguagem e as ilustrações utilizadas no CFESS Manifesta permitem a compreensão dos posicionamentos políticos do conselho pela categoria profissional, na medida em que se utiliza de conteúdo compreensível e ilustrativo. Essas estratégias são relevantes para politização da categoria profissional e a relação com os usuários, pois como enfatiza Iamamoto (2011), "[...] suas atividades dependem da competência na leitura e no acompanhamento dos processos sociais, assim como no estabelecimento de relações e vínculos sociais junto aos quais atua" (IAMAMOTO, 2011, p. 97).

A importância dos posicionamentos do conjunto CFESS/CRESS expressa no boletim CFESS Manifesta também é destacada pela categoria, tanto de profissionais, como de estudantes que entrevistamos na nossa pesquisa em que se destaca a ênfase na visibilidade que o conjunto CFESS/CRESS possui e a importância dessa visibilidade para poder disseminar esses posicionamentos. Outro aspecto importante diz respeito ao respaldo legal, conferido ao conjunto CFESS/CRESS, ao se posicionar sobre alguma temática 
que expressa a defesa de valores construídos coletivamente, como por exemplo: a descriminalização e legalização do aborto e a o fim da violência contra a mulher, contra o assédio sexual, entre outras expressões da questão social.

Além do machismo presente no cotidiano, o patriarcado também é incorporado e retroalimentado no tempo presente, se espraiando por todos os âmbitos da vida social e intensificando a escala de violência contra a vida das mulheres. A importância do posicionamento das entidades profissionais corrobora para que o feminismo seja materializado no fazer profissional, possibilitando o enfrentamento a valores conservadores presentes em todas as áreas de atuação. Ademais os posicionamentos das referidas entidades, também viabilizam a consolidação do projeto éticopolítico profissional, articulando as pautas dos sujeitos e movimentos sociais em luta, com os valores historicamente e coletivamente defendidos pelo conjunto CFESS/CRESS.

A popularização do acesso à internet provocou profundas mudanças na comunicação em âmbito mundial e com isso também trouxe transformações significativas para o Serviço Social, possibilitando as profissionais e estudantes uma maior aproximação com os canais de comunicação entre a categoria. A interação entre a base e as entidades aponta um caminho que pode ser aproveitado, ainda que existam muitos limites e possibilidades em tela impostos pelo fortalecimento do pensamento conservador.

Nas redes sociais é possível observar diversas críticas e comentários negativos quando o conjunto se posiciona em torno de algum tema polêmico na defesa de algum direito, seja no âmbito da autonomia e diversidade sexual, seja no direito a uma educação pública e presencial, entre outras pautas. Observamos que o posicionamento hegemônico da direção das entidades, muitas vezes, não corresponde ao mesmo posicionamento de diversos profissionais que estão na base. Além disso, identificamos, também, críticas ao posicionamento do conjunto CFESS/CRESS na defesa de pautas coletivamente e historicamente construídas, e que reafirmam os valores defendidos pela profissão na direção do projeto ético-político. Tais defesas são, por vezes, identificadas como extremas, dada a firmeza de não retrocedermos, mesmo diante dos fortes ataques sofridos. 
Vemos isto, por exemplo, na defesa de uma educação pública, laica, presencial, de qualidade e socialmente referenciada, e que se contrapõe ao Ensino à Distância. A defesa das entidades que representam a categoria, e a firmeza desses valores, levou o Conjunto CFESS/CRESS, juntamente com a ABEPSS e a ENESSO, em 2012 a promoveram a campanha "Educação não é fast-food. Diga não ao ensino à distância em Serviço Social”, cujo objetivo foi o de pautar politicamente a discussão acerca da realidade mercantilizante do ensino e suas consequências para a formação profissional. A campanha defrontou-se com relações sócio-políticas e econômicas conservadoras, que se materializam em perspectivas baseadas na modernização com apelo ao uso da tecnologia em favor do desenvolvimento e democratização do acesso ao ensino, sem revelar os reais interesses político-econômicos que perpassam tais ações. Com a crescente judicialização da questão social na sociedade brasileira, tivemos a censura à campanha, o que expressa, com clareza, a solução encontrada na atualidade para reprimir os conflitos sociais.

Contudo, por conceber os valores construídos coletivamente como parte da luta por outra sociabilidade, é fundamental fortalecer a direção hegemônica das entidades em tempos de retrocesso de direitos e de avanço do conservadorismo. Nesse sentido, o trabalho desempenhado pelo conjunto CFESS/CRESS mostra a pertinência da luta em defesa da profissão, dos direitos da classe trabalhadora e do projeto ético-político da profissão no decorrer da sua consolidação.

Outro importante instrumento de orientação, que normatizam a atuação profissional e que merecem destaque, são as Resoluções. Na página do CFESS, as resoluções datam desde 2003 até 2017 e seus conteúdos são diversos, tais como: o estatuto do conjunto CFESS-CRESS, homologação do resultado final de eleições das entidades representativas, regulamentação da supervisão de estágio, pagamento de anuidade, entre outros.

Todas as resoluções construídas pelo conjunto da categoria, por meio de nossas entidades representativas, expressam o acúmulo e a maturidade intelectual e política de nossa categoria. Elas representam, ainda, os avanços do conjunto CFESS/CRESS 
em defesa do projeto ético-político, pois refletem algumas das importantes conquistas de uma categoria comprometida com a disseminação de um "[...] projeto profissional vinculado ao processo de construção de uma nova ordem societária, sem dominação-exploração de classe, etnia e gênero [...]" (CONSELHO FEDERAL DE SERVIÇO SOCIAL, 2012, p. 24), conforme preconiza o $8^{\circ}$ Princípio fundamental do Código de Ética Profissional. Esses instrumentais.

\begin{abstract}
[...] resultaram de longos, amplos e profundos debates e expressam a construção democrática e coletiva que marca o Conjunto CFESS/CRESS. Estes instrumentos normativos são a materialização do Projeto ÉticoPolítico profissional construído nos últimos 30 anos no seio da categoria, haja vista que formulados para dar sustentação legal ao exercício profissional dos/as assistentes sociais, mas que não se restringem a essa dimensão. Pelo contrário, fortalecem e respaldam as ações profissionais na direção de um projeto em defesa dos interesses da classe trabalhadora e que se articula com outros sujeitos sociais na construção de uma sociedade anticapitalista (CONSELHO FEDERAL DE SERVIÇO SOCIAL, 2011, p. 11).
\end{abstract}

Embora consideremos os amplos e profundos debates entre o CFESS e os representantes dos CRESS (assistentes sociais de base e os que compõem a gestão dos conselhos regionais), demarcando o caráter democrático e coletivo do projeto éticopolítico e das pautas defendidas pelo Serviço Social brasileiro; não podemos perder de vista a correlação de forças existentes entre os divergentes projetos defendidos no interior da categoria, tendo em vista a heterogeneidade dos sujeitos que compõem a categoria profissional. Nesse sentido, reafirmar a importância das Resoluções construídas no âmbito do Conjunto CFESS/CRESS não implica na concordância total de todos os sujeitos que são representados pelos Conselhos Federal e Regionais.

Entretanto, o respaldolegal concedido a essas entidades(sobretudo ao (FESS) torna a observação desse instrumento obrigatória no exercício da profissão. Pois, embora as Resoluções não possuam força de Lei, são instrumentos normativos, construídos na perspectiva de reafirmar os valores e princípios defendidos pela 
profissão. Por isso, ainda que alguns profissionais, ou até mesmo componentes das gestões dos conselhos, discordem do conteúdo desses instrumentos, sua materialização precisa ser viabilizada.

Dentre as inúmeras Resoluções publicadas ao longo desse período, destacamos as que apresentam relevância para o feminismo e fortalecem o fazer profissional comprometido com as lutas feministas. São elas: a Resolução CFESS n²489/2006, que estabelece normas vedando condutas discriminatórias ou preconceituosas, por orientação e expressão sexual por pessoas do mesmo sexo, no exercício profissional do assistente social; a Resolução CFESS $n^{\circ}$ 594/2011, que altera o Código de Ética do/a Assistente Social, introduzindo aperfeiçoamentos formais, gramaticais e conceituais em seu texto e garantindo a linguagem de gênero; a Resolução CFESS n 615/2011, que dispõe sobre a inclusão e uso do nome social da assistente social travesti e do/a assistente social transexual nos documentos de identidade profissional; e a Resolução CFESS $\mathrm{n}^{\circ} 785 / 2016$, que dispõe sobre a inclusão e uso do nome social da assistente social travesti e da/do assistente social transexual no Documento de Identidade Profissional.

Enfatizamos e louvamos a iniciativa do CFESS em se manter atualizado e respeitando as mais diversas e diversos profissionais, de modo a assegurar o direito ao nome social, além de adaptar a linguagem voltada ao gênero e permanecer na luta contra a discriminação por orientação e expressão sexual. Desde 2006, através da publicação da Resolução CFESS n489/2006, que estabelece normas vedando práticas discriminatórias, que a categoria deu um grande passo na reafirmação do projeto éticopolítico profissional.

As Resoluções que garantem o nome social de assistentes sociais travestis ou transexuais evidenciam a importância do respeito à profissional de acordo com sua identidade. A linguagem de gênero modificada e atualizada nos materiais também garante a representação de todas as pessoas, contemplando a todos. Essa iniciativa é de fundamental importância, considerando que na atual conjuntura, o Brasil é considerado o país mais violento para a população LGBT, segundo reportagem do The New York Times (JACOBS, 2016) e pesquisa realizada pelo Grupo Gay da Bahia. 
Nesta perspectiva de respeito aos direitos humanos, aqui inscritos como o direito à representação das mulheres, travestis e transexuais, as legislações se configuram como um instrumento muito importante para a prática profissional, para a resistência ao pensamento conservador e para a efetivação dos direitos LGBT's dentro e fora do âmbito profissional. Estes documentos também se tornam um referencial político para outras categorias, de modo que inspira reflexões e possibilita modificações em suas respectivas áreas de atuação, de modo a garantir e efetivar o respeito a todos.

Outras publicações, para além das citadas, complementam e contribuem para a efetivação do feminismo no Serviço Social. Estas publicações são materiais construídos pelo CFESS de modo a orientar estimular a leitura critica da realidade em temas pertinentes ao exercício profissional. Produzidas desde 2006, as publicações têm abordado diversos temas diferentes no âmbito da formação e da prática profissional.

A primeira campanha do conjunto CFESS/CRESS foi em 2006, intitulada "O amor fala todas as línguas", na qual foi trabalhado o conteúdo em defesa da livre orientação e expressão sexual das pessoas através de cartazes e revista digital. Na pesquisa empírica com docentes e discentes, essa campanha foi a mais lembrada e citada nas entrevistas (50\% das estudantes e 50\% das docentes). Mesmo sendo antiga, construída há 11 anos, a campanha permanece relevante nos dias atuais, considerando que o debate sobre a orientação sexual ainda é permeado pelo pensamento conservador e homofóbico.

Em 2015, a discussão sobre o feminismo, a questão étnico-racial e a diversidade sexual foram abordadas no documento construído no $44^{\circ}$ Encontro Nacional CFESS/CRESS, que ocorreu em novembro de 2015 e agregou as bandeiras de luta do conselho ao longo dos anos. No âmbito da defesa da Seguridade Social, destacamos a reivindicação dos princípios de Yogyakarta, o Plano Nacional Cidadania e Direitos Humanos LGBT e o Plano Nacional de Saúde

9 Consiste em princípios sobre a aplicação da legislação internacional de direitos humanos em relação à orientação sexual e identidade de gênero. Ver mais em: CLAM. Princípios de Yogyakarta . Disponível em: <http://www.clam.org.br/uploads/conteudo/principios_de_yogyakarta.pdf.> Acesso em: 17 jul. 2017. 
da População LGBT, o posicionamento contrário ao extermínio/ genocídio da juventude negra, entre outras pautas interligadas.

No que se refere aos direitos humanos, as pautas referendadas incluíam o posicionamento favorável à legalização do aborto, considerado como questão de saúde pública e como direito sexual e reprodutivo das mulheres, o posicionamento contrário ao racismo e defesa das lutas pela equidade de raça, etnia, gênero e pela política de igualdade racial, o posicionamento contrário a todas as formas de exploração e discriminação de classe, gênero, raça, etnia, orientação sexual, identidade de gênero, idade e condição física, entre outros.

A iniciativa mais recente é a série "Assistente Social no Combate ao Preconceito" que objetiva.

[...] orientar e estimular assistentes sociais a uma compreensão crítica das variadas situações de preconceito que podem acompanhar os encaminhamentos cotidianos do exercício profissional, provocando a categoria a refletir sobre sua responsabilidade ética na defesa do projeto ético-político (CONSELHO FEDERAL DE SERVIÇO SOCIAL, 2016, não paginado).

Nesta série, alguns temas são discutidos tais como: o combate ao preconceito, o estigma do uso de drogas, racismo, transfobia e xenofobia. A atualidade das temáticas indica e reforça a importância do trabalho dos assistentes sociais na luta contra toda a forma de opressão e exploração e ressalta o compromisso das entidades nesta esfera.

\section{CONSIDERAÇÕES FINAIS}

A partir desta análise, podemos observar que a trajetória de luta do conjunto CFESS/CRESS permanece em constante construção pela categoria e pelas entidades profissionais. O comprometimento com a defesa intransigente dos direitos humanos e com a construção de outra sociabilidade sem opressão e exploração de classe, etnia e gênero, bem como alguns dos princípios fundamentais do Código de Ética profissional, tem sido respaldados pelas ações profissionais cotidianas, e pela democratização da informação da entidade para a categoria profissional. 
Da mesma forma, constatamos que embora o conjunto CFESS/ CRESS tenha trabalhado no fortalecimento do feminismo, da diversidade sexual e da questão étnico-racial em seus materiais, posicionamentos e espaços deliberativos, contribuindo para a construção de uma cultura feminista com a perspectiva crítica, frente ao avanço do neoliberalismo e da pós-modernidade, algumas destas pautas são rechaçadas pela categoria.

Tanto na pesquisa empírica, como em comentários nas redes sociais, é possível observar diversos posicionamentos de ataque à direção construída coletivamente no conjunto CFESS/CRESS. Contudo, é preciso considerar que o Serviço Social não é uma categoria homogênea e dentro da profissão há uma disputa pela direção política, por parte de profissionais conservadoras que coloca em chegue as lutas feministas, de igualdade racial e de diversidade sexual que vem se desenhando no âmbito profissional.

Nesse sentido, mesmo com duros ataques à direção política das entidades, é preciso manter a firmeza na defesa das pautas e lutas sociais que a categoria se insere, tendo em vista os instrumentos normativos e orientações estratégicas da profissão, que assim como o Código de Ética profissional, permitem um pensar e um agir crítico no cotidiano. Em tempos de avanço do pensamento conservador, é preciso resistir na contramão dos ataques que têm sido efetivados e pensar a comunicação como uma tarefa estratégica para a luta feminista.

Do mesmo modo, é preciso e importante frisar que os conteúdos referentes a raça/etnia e diversidade sexual também carecem de maior atenção da profissão. A limitação de estudos na área sobre estes conteúdos se configura como um dos desafios que o Serviço Social precisa enfrentar nos próximos tempos, em vista do genocídio da juventude negra e os casos de homofobia que ceifam vidas, cotidianamente.

\section{REFERÊNCIAS}

ABRAMIDES, Maria Beatriz; CABRAL, Maria do Socorro. A organização política do Serviço Social e o papel da CENEAS/ANAS na Virada do Serviço Social Brasileiro. In: CONSELHO FEDERAL DE SERVIÇO SOCIAL. 30 anos do Congresso da Virada. Brasília, (DF) 
2009. p. 55-78.

ABREU, Ana Cristina. A Política Nacional de Fiscalização do Conjunto CFESS-CRESS: avanços e particularidades. Revista Inscrita, Brasília (DF), n. 13, p. 57-63, 2013.

ASSOCIAÇÃO BRASILEIRA DE ENSINO E PESQUISA EM SERVIÇO SOCIAL. Diretrizes Curriculares da ABEPSS. Brasília (DF), [1996]. Disponível em: <http://www.abepss.org.br/diretrizes-curricularesda-abepss-10>. Acesso em: 5 abr. 2017.

BOSCHETTI, Ivanete. CFESS: O Projeto Ético-Político Profissional trinta anos depois: sentido e desafios. In: CONSELHO FEDERAL DE SERVIÇO SOCIAL. 30 anos do Congresso da Virada. Brasília (DF), 2009. p. 145-155.

CISNE, Mirla. SERVIÇO SOCIAL: UMA PROFISSÃO DE MULHERES PARA

MULHERES - Uma análise crítica da categoria gênero na histórica "feminização" da profissão, 2004, 203f. Dissertação (Mestrado em Serviço Social)-Programa de Pós-Graduação em Serviço Social, Universidade Federal de Pernambuco, Recife, 2004.

CISNE, Mirla. Feminismo e consciência de classe no Brasil. São Paulo: Cortez, 2014.

CONSELHO FEDERAL DE SERVIÇO SOCIAL. Série Assistente Social no Combate ao Preconceito. Brasília (DF), 30 set. 2016. Disponível em: <http://www.cfess.org.br/visualizar/noticia/cod/1300>. Acesso em: 15 out. 2016

CONSELHO FEDERAL DE SERVIÇO SOCIAL. Lei n.8662/93. Código de Ética do/a assistente social. 10 ed. rev. e atual. Brasília (DF), 2012.

\section{CONSELHO FEDERAL DE SERVIÇO SOCIAL. Legislação e} Resoluções sobre o trabalho do/a assistente social. Brasília (DF), 2011.

CONSELHO FEDERAL DE SERVIÇO SOCIAL. Política Nacional de Comunicação: Conjunto CFESS-CRESS. 2. ed. Brasília (DF), 2011. Disponível em: <http://www.cfess.org.br/arquivos/POLITICA COMUNICACAO_CFESS-CRESS.pdf>. Acesso em: 5 abr. 2017. 
IAMAMOTO, Marilda V. O Serviço Social na contemporaneidade: trabalho e formação profissional. 20. ed. São Paulo: Cortez, 2011. JACOBS, Andrew. Brazil is confronting an epidemic of anti-Gay violence. The New York Times, New York, 5 Jul. 2016. Disponível em: <https://www.nytimes.com/2016/07/06/world/americas/brazilanti-gay-violence.html?_r=1>. Acesso em: 17 jul. 2017.

NETTO, José Paulo. A construção do projeto ético-político do Serviço Social frente à crise contemporânea. In: CAPACITAÇÃO em Serviço Social e política social. Brasília (DF): CEAD, 1999. Módulo 01: Crise contemporânea, questão social e Serviço Social. NETTO, José Paulo. O Serviço Social e a tradição marxista. Serviço Social \& Sociedade, São Paulo, ano 10, n. 30, p. 89-102, maio/ago. 1989.

SAFFIOTI, Heleieth I. B. O poder do macho. São Paulo: Moderna, 1987.

SAFFIOTI, H. B. Gênero, patriarcado, violência. São Paulo: Perseu Abramo, 2004.

SILVA, Carmen; CAMURÇA, Silvia. Feminismo e Movimento de Mulheres. Recife: SOS Corpo; Instituto Feminista para a Democracia, 2010.

ZAÍRA, Ary. Masculino e feminino no imaginário católico: da Ação Católica à teologia da libertação. São Paulo: Annablume, 2000. (Coleção Outros diálogos). 